\title{
Service-learning as a Useful Supplement to Intensive English Programs
}

\author{
Varrick Douglas Jr. \\ Northern Virginia Community College, American Culture and Language Institute, Woodbridge, United States of \\ America
}

\begin{abstract}
This paper looks at the effects of service-learning on an Intensive English program. It examines English language participants at a community college who engaged in different service-learning projects over the course of one semester. Students found that service-learning helped them improve their English skills, increased their confidence when interacting with native English speakers, and gave them a rewarding experience of helping others. This paper argues that a service-learning component to English language learning curricula promotes enhanced language acquisition, as students are able to produce and receive authentic language outside the class while performing real-world tasks with meaningful purposes.
\end{abstract}

Index Terms -ESL, English as a second language learning, service-learning, academic English, intensive English programs, community service

\section{INTRODUCTION}

Service-learning at institutions of higher education has gained popularity in recent times (Molee, Henry, Sessa, \& Mckinney-Prupi, 2010; Gerstenblatt \& Gilbert, 2014; McClam, Diambra, Burton, Fuss and Fudge, 2008; Chupp \& Joseph, 2012). Service-learning is being used in a variety of disciplines, either as a capstone supplement to the program or as an integrated pedagogical component therein, with the purpose of both enriching students' academic development and making meaningful contributions to the community. There are a myriad of definitions for the term. According to the National Service Clearinghouse (2005), service-learning is “...a teaching and learning strategy that integrates meaningful community service with instruction and reflection to enrich the learning experience, teach civic responsibility and strengthen communities" (McClam, Diambra, Burton, Fuss \& Fudge, 2008, p. 237).

Ryan and Callahan (2002) see service-learning "as a reciprocal relationship that merges both field experience and sustainable community service, to offer learning opportunities that link academics to service, so that both students and the community partner benefits" (quoted by Hildenbrand \& Schultz 2015 p. 262). In addition, Scott (2008) describes service-learning as "an educational experience that brings course content to life by applying classroom theories, concepts, and skills within a community" (Byers \& Gray 2012, p. 257). Bringle and Hatcher (1995) define it as

a credit-bearing education experience in which students participate in an organized service activity that meets identified community needs and reflect on the service activity in such a way as to gain further understanding of course content, a broader appreciation of the discipline, and an enhanced sense of civic responsibility. (as cited in Gerstenblatt \& Gilbert, D. J.,2014, p. 1039)

Jacoby (1996), on his part, calls service-learning "a form of experiential education in which students engage in activities that address human and community needs together with structured opportunities intentionally designed to promote student learning and development" (as cited by Amerson, 2010, p. 18). Jacoby (1996) as well as Mass-Weigert, (1998) Kinsley (1994) and Berson (1994) also suggested that service-learning is a "pedagogy which involves academic study linked to community service through assignments that require some sort of structured reflection so that each reinforces the other, with the benefits far exceeding those of service or learning by themselves" (Elwell \& Bean, 2001, p. 47). Finally, the National Youth Leadership Council (2017) defines service learning as "an approach to teaching and learning in which students use academic knowledge and skills to address genuine community needs" (What is Service Learning?, 2017).

Thus, based on the literature review, we can essentially assert that service-learning is a pedagogical strategy that involves the application of classroom instruction to some form of public service, with the mutual objective of reaching student learning outcomes while fulfilling a need in the community. It is also a way of applying theory to practice that benefits the greater good - one of the highest aspirations of pedagogy. Yet with its rising recognition as a useful form of cognitive training in higher education, it has only been used sporadically in English language learning programs, and very little discussion in the related literature has taken place about ESL college students participating in service-learning (Elwell \& Bean, 2001).

Second language acquisition theory claims that language learning does not necessarily take place in a classroom. Second language acquisition occurs in living unscripted linguistic environments where the learner is constructing a grammar through codified input (Gass \& Selinker, 2001). In formalized language instruction, a teacher serves simply as a facilitator and source of reference for second (third, fourth, etc.) language development. The student must have an 
opportunity - even necessity - to use the language outside of the structured setting of a classroom in order to truly acquire and retain it. What better means, then, to aid and ensure this than through service-learning?

When implemented properly, service-learning can provide English language learners (ELL) with real world situations to use the language constructively. In addition, it can provide them with an authentic cultural experience that will not only inform them of the dominant social norms of the country they are residing in, but will also enrich their lives with the positive experience of helping others. What follows is a review of the literature on service-learning and then an elaboration of a service-learning experiment conducted by my own institution.

\section{LITERATURE REVIEW}

Not surprisingly, service-learning is most commonly implemented in social service, teacher training and nursing degree programs. Students are typically required to enlist in community services that model the profession in which they are trained. McClam, Diambra, Burton, Fuss and Fudge (2008) suggest that service-learning should involve learning through active participation, structured time for reflection, the opportunity to apply learned skills, and knowledge of real life situations. It should also involve learning that extends beyond the classroom. In their study, university majors in the field of Human Services engaged in a semester long assignment of assisting patients at a residential psychiatric facility for adolescents. Students formed professional-client relationships with patients as they assumed the formal duties of psychiatric social-workers. Students were given pre-experience written reflection assignments to address their expectations and concerns. Then, upon completion of the service-learning, they were given post-experience written reflection assignments to measure their personal growth and formal understanding. McClam, Diambra, Burton, Fuss and Fudge's (2008) findings showed that "students exposed to well-planned experiential learning activities overcome initial concerns, develop professional confidence, and demonstrate learning at an advanced level when confronted by real and meaningful work-place challenges" (p. 247).

Byers and Gray (2012) conducted a study of service-learning in an elective Masters of Social Work course in which the students who actually continued to engage in civic activities in the community they were assigned after the course was completed. Their prolonged commitment was not a requirement of the course, nor had any contribution to their academic standing. One of the most distinctive aspects of this research is that rather than looking at attitudinal measures of self-reporting, the data in this research looked at observable behavioral reactions to service-learning. The majority of students who took the course and participated in the qualitative interviews decided to return to the community they helped for further civic activities. More students may have returned had the university offered continued structured activities in the community. Byers and Gray (2012) argue that service-learning should be included in the curriculum because "it bridges the "wide gap' between classroom and practice" (p. 264), and that "service-learning is a valuable method for transforming impressions of communities, defining macro-practice.... and fostering civic engagement" ( $p$. 266).

Hildenbrand and Schultz (2015) explore the effects of service-learning on teacher education. Teacher candidates were assigned to work with community organizations that provided social aid to economically disadvantaged families, people with disabilities, and English language learners. One of the objectives was to provide teacher candidates with the opportunity to work with populations that experienced frequent social inequities. Participants were able to experience real community based problems, learn from them, and eventually work toward solving them. According to Hildenbrand and Schultz (2015), "each family identified a problem that needed to be solved, and small groups of teacher candidates investigated the root cause of the issue and creatively worked with families to resolve or better their situations" (p. 269). The uncertainty of each family's situation as well as the nature of the complex issues that belied these conditions drove teacher candidates to higher levels of flexibility and critical thinking - two crucial aspects of pedagogy. After their service-learning component, most teacher candidates said that the process enhanced their classroom studies, helped them learn to work with a group, improved their civic awareness, and overall added value to the course.

Gerstenblatt and Gilbert (2014) also designed an elective service-learning course that connected students to disenfranchised members of the community. The pedagogical approach of the course was based on three elements: working with existing structures of university-community partnerships, creating ongoing projects that transcended the boundaries of semesters and academic disciplines, and reflecting on larger political economic and social justice issues. The researchers note that student learning, reflection and reciprocity between students and the community should have equal importance in service-learning. The objectives of the course aimed at developing the abilities of students to engage in complex analysis, enter collaborative community relationships, apply specific methods of theories and research, perform civic actions, and practice transformative critical thinking. They claim that "as part of the course objectives, students were challenged to think imaginatively and creatively about public problems and their solutions, particularly from a multidisciplinary perspective in partnership with community members" (p. 1047). Students initially gathered ideas about needs from rural community residents with $21 \%$ of its members under the federal poverty line. Students then formed groups based on their interests, and worked with local government and non-profit organizations to come up with long term solutions in which students of future semesters would continue to engage.

Amerson (2010) examined the self-perceived cultural competence of undergraduate nursing students after the completion of a service-learning project with local and international communities. Students were required to do a cultural assessment of specific Latino communities in the U.S. and Guatemala, and then develop a culturally appropriate 
plan of healthcare. They conducted anthropologic style interviews with community informants about their perceptions of healthcare issues in the community. Afterwards, they worked with community leaders to create a plan for educating the population and implementing better healthcare procedures. Students - who mostly were not fluent in Spanish-even learned key phrases in Spanish to speak with patients about medication and proper health habits. The study findings suggested that nursing students perceived an increased competency in their cognitive, practical and affective abilities related to working with the assigned cultural population. According to Amerson (2010), "introducing students to cultural values and beliefs relevant to their target population initiates an awareness of the role culture plays in decisionmaking and healthcare practices" (p. 22).

While cultural competence is within the capacity of service-learning projects, sometimes all that is needed is basic cultural awareness. Fitzgerald (2009) analyses service-learning as a means to teach multiculturalism and promote social diversity among a largely homogeneous white student population at a U.S. university in Texas. As part of a larger project to encourage students to work with people from other cultures and linguistic backgrounds, Fitzgerald oversaw an ESL/Literacy service-learning course, whereby eligible participants offered volunteer language tutoring to the local Hispanic community. The overall project had two objectives. The first was to create a course that included tutoring as a service-learning element and fulfilled an undergraduate requirement, specifically those who were studying English or Education. The second was to create volunteer work for undergraduates. The research Fitzgerald conducted sought to examine students' attitudes towards diversity before and after a semester of tutoring. Pretest and posttest were conducted through anonymous online surveys. Results showed that students had a more positive attitude about diversity after regularly tutoring ESL residents of the community.

Marlow (2007) also describes a service-learning component to a college course where ESL students are the recipients. Native English speakers and international ESL students spent 30 hours together over the course of the semester engaging in extra-curricula activities of their choosing. Some of the extracurricular activities included attending campus-based events, community based events, going to museums, going bowling, and practical assistance like looking for an apartment, or opening a bank account. In addition to extra-curricular activities, there were structured tutoring sessions with context based language activities in class. These were opportunities for ESL students to apply concepts that they learned in their core university courses with the aid of their service-learning partners. Both parties benefited by gaining either linguistic or cultural knowledge from the other.

Sperling (2007), however, is critical of how multicultural service-learning has become a viable means to "teach about the complexities of our multiethnic, multiracial world" (p. 309). The author points out how the majority of students in multicultural service-learning are upper-middle class white students, and that often the quantity of participant hours take precedence over the qualitative and meaningful objectives of service. In a country like the U.S. where racial and identity politics still remain relatively volatile, Sperling (2007) notes that having white postsecondary students do servicelearning in black and Latino communities can create paternal power relationship that only serves to reinforce a white hegemony. With good intention, most service-learning programs do attempt to fulfill identified community needs. However, programs that employ multicultural service-learning should be aware that

"it is difficult to skip over the word needs without wondering how it affects participants. Even if they are instructed to approach their service from a social change orientation, participants still are being implicitly taught to dichotomize the world into the needy... and the benevolent service providers." (Sperling, 2007, p. 314)

Thus, while the objective may be in the good intentions of broadening the cultural perspectives of students, we not only stand the risk of presenting them as outsider authorities inadvertently imposing their cultural values on the local population, but without proper critical vetting of reflection methods, students may walk away with only a superficial understanding of their service-learning experience. Other researchers like Chupp and Joseph 2010 also speak to the potential of reinforcing stereotypes and paternalism as a negative side-effect of service-learning.

Still, when power relations and biases are apparent and critically reflected upon throughout the process, servicelearning through interaction with other cultural groups can be enlightening. Hagan (2004) practiced service-learning through ESL tutoring as a component of her clinical psychology doctoral program. Hagan, a white American female, became critically aware of the implicit hierarchy between herself - an English speaking native of a privileged classand her tutee, a Korean working class mother of two. Throughout her experience tutoring, the author explored the applicability of John Berry's (2001) theory of acculturation. According to his theory, when a minority culture comes into contact with a dominant host culture, there are four strategies that they can employ to cope with the process of acculturation. The minority ethno-culture group can: a) integrate, which involves mixing their own cultural identity with the host culture, b) assimilate, which involves totally embracing the host culture, c) separate, which is the attempt to remain steadfast in their own cultural ways and avoid the host culture entirely, and d) marginalize themselves, which is a retreat from both their own culture and the host culture. International students are no different. Integration, even if temporary, would be the ideal outcome to stave cultural shock. Hagan's experience with her ESL student not only helped the student get a better grasp of American society through language and practice, but it also allowed the author to reflect on her own implicit prejudices and subconscious cultural practices.

The effects of service-learning on participants can vary. Mahasneh, Tawalbeh, Al-Smadi, Ghaith, and\& Dajani, (2012) conducted a study to test service-learning as a pedagogical and learning strategy. Specifically, the authors explored the degree to which service-learning fostered a connection to their classmates and university, invoked their 
sense of responsibility to the greater community, and contributed to their professional development. Their findings concluded that service-learning helped students to apply theory to real-life, built self-confidence, facilitated teamwork skills, and enhanced communication and social skills. The experience as a whole created positive perceptions of the community and the idea of community service. In addition, the community partners that hosted the students reported high-levels of satisfaction with student service.

However, service-learning is not necessarily easy or always as desirable. Darby, Longmire-Avital, Chenault and Haglund (2013), for example, performed a study that examined the factors that increase and decrease students' motivation for carrying out service-learning throughout the semester. Among these were gender, student expectations, and time. Female students generally began with higher levels of motivation that declined steadily, while male students experienced a hike in motivation midway through the semester. Students were motivated by self-expectations, and their community partners. The more these aligned, the higher the motivation rose. Finally, students were concerned about fitting this extracurricular activity into their already busy schedule. The authors found that aspects such as having an interest in helping people, forming positive relationships, gaining a sense of community responsibility, and all around enjoying the experience increased their motivation. Other aspects like communication problems, integrating learning outcomes of the course and the service-learning experience, as well as transportation issues and schedule demands decreased motivation. In the end, the research showed the tendency for motivation to decline for all students as the semester progressed.

However, a change in geographical context in combination with genuine humanitarianism can overshadow the aforementioned disincentives. Bamber and Pike (2013) advocate for international service-learning whereby students participate in community service in another country. This service-learning takes the form of volunteering for programs that are aimed at solving problems related to poverty and social injustice. They see international service-learning as "a form of ecological engagement with aesthetic, moral and spiritual dimensions that is enacted through participation with the lives and 'worlds' of those living in different countries" (p. 536), Bamber and Pike (2013) point out the ethical aspect of service-learning where students contribute to creating a more equitable and sustainable society. Language learning, cross-cultural awareness, and all round personal transformation are the benefits they see from being exposed to another culture for service-learning. Their qualitative research looked at how students described their ongoing experience of international service-learning. Nearly all students in the study described their experience as life changing. They saw themselves and the world differently, as they reassessed their value after working with people less fortunate than them.

When applied to English language learning, service-learning has proven to be an effective teaching strategy. Heuser (1999) used service-learning for Japanese ESL students as a capstone project in a sheltered-content sociology class to enhance students' awareness of homelessness in the United States. Sheltered-content combines English language instruction and specific academic content. After preparing students through readings, written responses, role plays, and poverty simulations (students were grouped into families and assign poverty-level wage jobs and a monthly budget), students were guided on a three day service-learning weekend at a youth drop in center, a homeless shelter, a women's crisis center, and a residential facility for mentally ill adults. As part of their reflection, students had an oral discussion in which they related sociological concepts to their experience. Then, they were asked to write a letter to a friend to describe their experience to a friend as they applied the theories they went over in their discussion. Heuser (1999) asserts that "a service-learning model boosted students' motivation, because they could apply language and content knowledge to their actions in testing whether their experiences had supported or contradicted what they had learned in class" (p. 67)."

Minor (2001) had ESL students engaged in service-learning as an integral part of their institution's program. Each week, students went to places such as soup kitchens, elementary schools, or retirement centers and performed needed tasks. Then, they discussed their experience in class and performed further research about the issues responsible for the conditions of the people they were serving. Minor (2001) offers a list of practical advice about setting up a servicelearning component such as spending a few consecutive weeks at a the same worksite to develop rapport or making sure the activities students are engaged in involve personal linguistic interaction with others.

Elwell (2001) specifically advocates for service-learning for ESL students at community colleges. The author asserts that the academic component of service-learning is based on the reciprocal nature of the process. While students are providing a service, those being served are teaching lessons to those who serve them. One can imagine that in the case of ESL, the major lessons being taught involve task-based aspects and contextualized language use. Elwell (2001) notes that service-learning not only connects students with the community, but it also connects academic disciplines, facilitates communication among students, allows students to align their personal passions with academic requirements, and generates empathy for the vision of a healthy community. The author also notes that ESL services in learning have only been used sporadically in programs designed to increase language proficiency. While service-learning at the postsecondary level has received a significant amount of attention in the literature, very little discussion has taken place about ESL college students participating in service-learning (Elwell, 2001). This researcher had an intermediate level class read John Steinbeck's "Of Mice and Men”, as well as engaged them in research projects on the life of this author and on the social conditions of migrant labor of the time that inspired the novel. The students' service-learning project was a local drive to collect food, infant care necessities, and school-supplies for migrants that had been economically 
devastated from a recent crop failure. According to Elwell, "through their reading of Steinbeck's novel and related reflective academic activities, the students had become fascinated by the situation of California's farmworkers, seeing it as an extension of a historical economic situation that has endured since Steinbeck's time" (p. 53).

Glicker (2006) uses service-learning as an integral part of an noncredit elective writing course for adult ESL students who need academic skills to successfully transition to students into the community college. Students worked as mentors and tutors to help level ESL students for 2 hours a week during the 12 week course. As part of their reflection exercises, they kept journals and had weekly meetings to share their experiences with each other. According to Glicker (2006), "the course was designed so that students could develop a deeper awareness of their own learning processes as well as deepen their commitment to the college learning community" (p. 42)." As a result, "service-learning helps students become the architects of their own academic futures while assisting less proficient learners" (p. 45).

In a small rural school district in Central Nebraska, U.S.A., Russell (2007) implements service-learning into her ESL curriculum by having students aid the extensive ESL population of the area. Students, through their own deliberation, decided to create a mini Spanish/English phrase book to give away to community members. Russell notes how servicelearning creates opportunities for applying problem solving skills while developing their English, as well as their research, skills. In Russell's (2007) service-learning requirement, students were encouraged to take initiative. They divided themselves into groups and assigned each other tasks. One of them was to create and distribute a questionnaire in English and in Spanish to distribute, in order to get input from the community about what should be in the phrasebook. Others focused on contacting local businesses for donations to print the booklet. The researcher uses the term "collateral learning" to describe the outcome because, in addition to developing new relationships, students improved their English skills. As they communicated with the community, they were able to have authentic experiences with native speakers beyond the classroom. The author also points out to the reality that this kind of service-learning motivates students to learn because they get the opportunity to apply what they learned in a meaningful way. Also,, they are able to address problems they care about outside the classroom, and they gain a connection and ownership of the community in which they reside. For international students who often feel the isolation of cultural shock, this means an invaluable sentimental asset.

When language development is a significant part of service-learning experience for ESL students, students are capable of getting much more out of it. Leeman (2011) stresses the need for critical analysis of the ideological and material impact of service-learning programs. The author refers to the tendency of some programs to simply use local communities as a language resource rather than orienting the service to the community's need. The author additionally points out that language learning is not the only aspect that service-learning offers: there is also community knowledge available to be learned. According to Leeman (2011), "ideally, service-learning programs linked to foreign language learning would use classroom activities and discussions to help students develop critical consciousness regarding cultural, social and political issues related to multilingualism and linguistic activities" (p 301.). The author then gives two examples of successful language linked service-learning programs in the U.S. among heritage Spanish language learners (that is, first, second and third generation Latino immigrants with varying degrees of linguistic competency in Spanish). In the first case, students majoring in health-related fields took Spanish courses that focused on medical terminology, translation, literacy studies, and sociolinguistics. Then they worked in local medical clinics that served the Hispanic population to provide diabetes prevention information and offer translation/interpretation services. This provided students with the opportunity to critically analyze health disparities as well as the patterns of discrimination in American healthcare that emerge from language policies and ideologies. In the second example, students operated an after--school Spanish literacy class for young heritage Spanish speakers at a local elementary school. According to Leeman (2011), three critical connections were made between: (1) university students and the children's parents and teachers, (2) classroom content and authentic agency and (3) younger heritage speakers and older more experienced models of linguistic retention.

In addition to the crucial connections that service-learning makes between the university and the community, at the heart of it there is a moral obligation. Lovat and Clement (2016) situate service-learning in "values pedagogy". This means a pedagogy that incorporates civics and citizenship in the curriculum namely through service-learning. They do not see education in social values as simply as a moral imperative, but as a pedagogical one. Their focus is specifically on the element of value pedagogy that nurtures empathic character and affective self-management which in turn develops social intelligence. Service-learning, according to Lovat and Clemet (2016) "can be seen to accord with neuroscientific notions concerned with sociality as a feature of human development, social intelligence as an artifact of cognition, and the nurturing of empathic character as essential to effective teaching and learning" (p. 116). They see enhanced empathetic social consciousness as an essential learning outcome of the civic involvement that servicelearning requires. In addition, the dual achievement of increasing student agency in the environment while achieving the larger objectives of formal education is part of what defines service-learning.

Chupp and Joseph (2010) argue that service learning is at its most successful when there is a triple impact that include the student, the university and the community. When there is a palpably positive change among each of these parties, the effects of service learning can be far reaching and ongoing. Chupp and Joseph then categorize four approaches to service learning that have different outcomes as well as beneficiary recipients: traditional, social justice, critical and service learning with institutional change. Traditional is the most basic form of service learning. It involves 
the community service that "enhances academic learning through student action, reflection, and application" (p. 192). The primary beneficiary of this approach is the student. Social justice service learning has a moral element that fosters critical thinking about societal issues and builds awareness of the need for social change. In this approach, both the student and community benefit. Critical service learning is similar to social justice service learning in that they both promote awareness of deeper rooted societal malaise. Yet the main difference, according to the author, is that critical service-learning calls for immediate action for social change in fundamental ways. Finally, service learning with institutional change is "[s]ervice learning as an opportunity to examine and change institutional structures and practices" (p. 192). Here, the student, the community and the university benefit altogether. Chupp and Joseph argue that with all the work that goes into establishing relationships with community partners, organizing activities, and creating the curriculum, it would be a waste to only focus on student learning outcomes. Faculty and administrators in their various departments could use this as an opportunity for professional development and a means to apply academic resources to address real world issues. This serves to reinforce the very student agency for change that its service learning curriculum purports.

When analyzing the literature there are a few common themes. The first is the reciprocal relationship between the service and the student providing the community, with what the community is teaching the student, service-learning is holistically effective. Kelly (2013) refers to it as collaborative service-learning. The author makes the distinction from community service by noting that while community service involves unpaid work designed to benefit the community in some way, in addition to this, collaborative service-learning involves "the integration of formal and informal components" (pg. 82). That is, the student gives to the community and the community informs the student.

The next theme is the conceptual and social connection facilitated by service-learning. Conceptually, students are taking static textbook instruction and applying it to dynamic situations. Not only does this connection reaffirm what they have studied in the academic curriculum, but it also fosters critical thinking as students evaluate to what extent (if any) certain concepts apply to the issue at hand. Socially, valuable relationships are being made on both the micro and macro level. At the micro level, students are connecting with people of a myriad of backgrounds who can offer them the wealth of their experience in the community. If students are working in groups with their peers, they gain and or strengthen their cooperative skills. At the macro level, the university or college is able to create structural ties to the community that can reap immediate social and economic benefits to the outside organizations involved.

Finally and most importantly, reflection is the essential learning factor of service learning. Its implantation-whether through writing and/or discussion - and its quality is crucial to successful service-learning. This will truly determine what valuable pieces of knowledge students will walk away with from the experience. Molee, Henry, Sessa, and Mckinney-Prupi (2010) examine and describe the DEAL model for assessing student learning in service-learning courses. The DEAL model is an acronym for a three part process that involves 1) describing experiences, 2) examining experiences through the framework of course learning objectives and 3) articulating their Learning through reflection (Ash \& Clayton, 2004; Ash, Clayton, \& Moses, 2007; Jameson et al.,. 2008, found in Molee, Henry, Sessa, \& Mckinney-Prupi,, 2010). This model was applied through writings and extensive instructor feedback. Students were given prompts to vividly describe events and actions that they engaged in service-learning, relate real life experience to theoretical concepts and are required to make constant revisions throughout the process. The authors found that "the assessment rubrics of the DEAL Model enable reflection to be used to determine what students are learning, how well they are learning it, and even how their learning compares to learning in other pedagogies" (p. 250). Chupp and Joseph (2010) refer to Hatcher and Bringle's (1997) set of guidelines for effective reflection, "link experience to learning objectives, give guidance to activities, schedule activities regularly to expand the service experience over the course of students' development, allow feedback and assessment and include clarification of values" (p. 194). They also note the four phases of Kolb's $(1981,1984)$ experiential learning cycle: “concrete experience, reflective observation, abstract conceptualization, and, finally active experimentation" (194). In essence, the reflection component of service-learning should be aligned with the overall learning process of human beings. How it is structured and implemented will determine the efficacy of service-learning.

\section{Background}

The setting of the initial attempt at service-learning for ESL students was a community college that offered an intensive English program meant to prepare international English language learners for college in the United States. These courses ran parallel to the college semester and ranged from introductory English to Intermediate English classes that ran a total of 126 hours per term. This particular campus hosts around 150 students a year.

Typically, at the end of each semester, students are required to perform a final project of some sort that reflects the culmination of their language learning. One instructor of a combined Beginner and High Beginner class with a total of ten students decided to intertwine an extra-curricular element to this final project that included service to the community. The instructor divided students into groups at the beginning of the semester and had brain storming sessions about possible initiatives. Some of these ideas included: a school food or clothing drive in which proceeds would be donated to a local charity, cleaning up a dirty public space, getting permission to plant trees, and volunteering at the local library

There were obvious obstacles to achieving these goals. Some students, for example, did not have time outside of the class to volunteer to clean a park. And getting permission to plant anything anywhere in our city of residence is a bureaucratic nightmare. Nevertheless, students made attempts to do so and investigated the matter. This meant finding 
people, asking questions, hashing out dilemmas - in short, using English. Throughout the semester, the instructor regularly received progress reports from the groups and provided incremental feedback that organically shaped the final product of their projects.

In the end, the students hosted an event on campus that highlighted the focus of their projects. One group had a "Plant a Tree Project". Though they were not physically able to plant a tree, they created brochures on how to do so, and had games in which the prizes were potted plants. Another group had a "Travel Around the World" exhibit in which students displayed clothing and cultural artifacts of their home countries. They also gave free food to campus from the respective cultures, which they prepared themselves. They held the event for one hour in the campus cafeteria and received a lot of attention. As part of their final presentation, they provided visual and physical artifacts of their experience in community service. Since this was the first time doing something like this for both the instructor and the students, it was last minute, a bit haphazard, and was limited to on- campus activities. However, it served as a template to formalize a community service element into the curriculum at all levels for the following semester.

\section{PARTICIPANTS}

A total of 28 community college ESL students in an Intensive English program took part in the service-learning community project (SLCP). Students, males and females, were in three separate mixed level classes: (1) Introductory \& Low Beginning English (2) Beginning \& High Beginning English and (3) Low Intermediate \& Intermediate English. All but 1 student were taking a full time 20 hour a week class load that consisted a reading and writing course and a speaking and listening course at their respective levels. Students were of heterogeneous linguistic background from various parts of Africa, Latin America, Asia and Europe. With the exception of three middle aged participants, students were young adults under 25 years of age.

\section{Methodology}

At the beginning of the semester, instructors were given assignment sheets that entailed the rationale, objectives, suggested methodology and grading of the SLCP. The instructors were told that they could scaffold the projects by setting parameters, offering examples and suggestions, and giving logistical support beyond the students' knowledge of operations. Students were told they could work in groups depending on class size, or that the class could work together as a whole. To alleviate the legalities of field trip wavers, students acted independently, outside of class time hours.

Throughout the semester, students provided weekly or biweekly updates to the instructor in the form of either a brief written report, a brief class presentation, or both. The purpose for these briefings was to provide the class and instructor with updates on their progress, as well as present any new challenges or questions they may have had. In addition to students having regular briefings with their instructors, I had regular briefings with the instructors as well to monitor progress and offer advice. As part of a final project at the end of the semester, students gave group presentations with artifacts (videos, pictures, flyers, etc.) showing the highlights of their experience throughout the SLCP. Finally, students were given surveys rating the usefulness of the assignment altogether.

\section{Project Results}

The Introductory and Low beginning class worked as a group to create an informational pamphlet about the available college facility for new international students. They conducted interviews with other international students on campus so as to find out about some of the initial problems they had with the college when they first started. Afterwards, they went to the respective facilities and interviewed the managers on how to use them, compiled the information along with photos, and printed some copies to distribute and keep in our office for reference to give new students.

The Beginning and High Beginning level students helped a local church package and distribute food for the needy. Low intermediate and intermediate students worked through a language conversation club to help other students improve their English speaking.

\section{SURVEY RESULTS}

The survey included eight questions with inquiries about the nature of their SLCP, something new they learned with the experience, if they thought it helped improved their English, the hardest and most memorable moments, if they felt more confident in a community of English speakers since the start of the SLCP, and if they would do another SLCP of their own volition. Out of the 17 students who completed the survey (the low intermediate and intermediate students did not complete surveys), all but 2 said they believed the SLCP helped improve their English. All students said they felt more confident in their English speaking skills and 14 stated that they would like to do another SLCP if given the opportunity. Some of the new things students stated they learned from the project were working as a team, new vocabulary, and practical skills related to their SLCP (e.g. how to make a brochure or how to organize food inventory).

\section{DISCUSSION}


The limits of using student surveys to measure the success of this SLCP is two-fold. First, students accessing their own language development stand the risk of being undermined by subjectivity. Simply because students stated that they felt that their English improved or had more confidence using the language does not necessarily mean that they understand or speak it any better. Second, while there were quantitative values within the survey, the very nature of it was qualitative, which can question any statistical margins of consistency when measuring its success. Notwithstanding, the fact that students in the intensive English program did pass the course through the program's standard evaluation process and the majority reported overall positive learning experiences through the SLCP should serve as enough evidence that its implementation was successful in reaching its objectives.

Employing service-learning for intensive English programs appears as though it should be commonsensical for any curricula for several reasons. The first is purely linguistic. Exposure to the language in an uncontrolled environment in combination with instruction contributes to proficiency. Students get the opportunity to apply and affirm semantic knowledge they gained in class while constructing and accessing a grammar through interaction with other speakers of the language. In addition, students will be using the language to complete a meaningful real world task. This means they must employ problem solving skills while utilizing rhetorical agency to do so. This is an essential facilitator of second language development (Gass \& Selinker, 2001).

Another reason why service-learning should be a part of intensive English programs has to do with cultural proficiency. Many, if not most, students intensive English programs are foreign students. Those who are not foreign may be second generation immigrants who have limited exposure of their own cultural enclaves in the country. Servicelearning provides them with the opportunity to explore the larger milieu of their surrounding English speaking community. Students get a better understanding of how to socially navigate the unfamiliar cultural terrain. They learn customs, mannerisms, behaviors and even dialects different than the ones they are accustomed to. Whether students choose to try to assimilate or integrate within the new environment, service-learning offers the chance for them to go beyond their social comfort zones and experience the country as it truly is.

Separate but not unrelated, the quality of the service-learning increases the overall quality of language education which can encourage both student matriculation and retention in a program. Glicker (2006) notes that "service-learning may provide a conduit for increasing matriculation of diverse communities at the college as well as university level" ( $p$. 40), and further, it can "help build retention and empower students. By combining knowledge of a variety of effective ESL instructional approaches with an innovative service-learning curriculum, the students can learn how to more effectively manage their time and their linguistic capital for maximum benefit" (p. 45). While it may not be true of all English language learners, being able to have a positive memorable experience outside the class, but still related to a program which helps them get the most out of their language learning endeavors, leaves a lasting impression about the school in general. Most of our students responded on their surveys that they would like to engage in another SLCP, and also described the kind of service-learning they would get involved in if given the opportunity. A program that advertises regular community engagement to enhance the language learning experience is bound to be enticing to foreign students eager to learn English in another country.

And while this article argues for service-learning in Intensive English programs with international students specifically, there is no reason why English language courses at any capacity for residents should not utilize it as a linguistic tool. Classes for adult residents and citizens learning English as their second language could also be improved by including a service learning element. In fact, it could even be argued that resident students and their communities may benefit more from this. Not only would students have the potential of orchestrating projects that bridge language gaps in their own community (think of the mini Spanish/English phrase book that Russel's (2007) student created to give away to community members), but the service learning element could exemplify things that they are already trying to perform in English within their communities. Imagine, for example, a Spanish mother who is taking English classes to better communicate with her child's elementary school instructor doing a service-learning project that involved being an informal elementary school teacher's assistant.

Finally, as much of the literature on it iterates, service-learning has a moral dimension that emphasizes institutions giving back to the community. Many students who participated in our SLCP expressed a general satisfaction for simply being able to help people in need as they practiced English. In general, foreign students who visit wealthy English speaking countries like the United States may often be stunned that there are even people in need to help. Exposing them to this reality gives them a more accurate picture of how the world works. In addition, having students volunteering locally can promote sentiments of pride and inclusivity, as international students take stake in their immediate communities even though it is not their home country. The more they get involved, the less likely they may feel isolated in a foreign culture and space.

\section{CONCLUSION}

This paper examined the effects of service-learning when implemented in an intensive English program curriculum, and argues that it should be an integral component of all such programs where possible. Service-learning has proven to enhancemence the language learning process, as it requires students to use the language beyond an academic setting. Recommendations for future research would include exploration of how a more structured lexical schema prepared by instructors may enhance language learning. Students could be provided with a list of words and phrases relative to the 
service-learning task and environment they have chosen or been assigned. The correlation of vocabulary acquisition and service-learning might provide further insight on receptive and productive learning. Also, technologically creative forms of reflection might be employed to examine whether this increases students capacity to learn English. Students can keep blogs, use various online platforms to post audio-video recordings of their service-learning or work collectively to create a wiki page about their experiences. All of this would accompany a final product that would measure the success of the process. Finally, while preexisting university ties for community service-learning are certainly beneficial, it might be worth considering giving students options to research their own forms of service. Darby, Longmire-Avital, Chenault and Haglund (2013) note that the goals and direction of a community partner may not be aligned with the students objectives or interests, which could lead to a lack of motivation to complete the project. On the other hand, Kelly (2013) points out that students may be left with too much burden to find an organization and apply the objectives of the assignment given. This can cause unnecessary anxiety and frustration. Thus, a healthy balance of freedom and structure are necessary.

Altogether, when done properly, placing service-learning as a permanent fixture in an intensive English program curricula can enrich students' educational experience. It offers them the opportunity to immerse themselves in a foreign culture as they advance in their academic track, receiving both structured intake of information in class, and dynamic experiential intake of information outside the class. Students have the opportunity to create positive relationships and learn to work as a team as they gain the moral satisfaction of providing a service to their community. And, most importantly, they stand a better chance of achieving the objectives of all intensive English programs, that is, to gain proficiency in the language.

\section{REFERENCES}

[1] Amerson, R. (2010). The impact of service-learning on cultural competence. Nursing Education Perspectives (National League For Nursing), 31(1), 18-22.

[2] Bamber, P. M., \& Pike, M. A. (2013). Towards an ethical ecology of international service learning. Journal of Curriculum Studies, 45(4), 535-559. doi:10.1080/00220272.2012.675354.

[3] Berson, J. (1994, Jun/Jul). A marriage made in heaven: Community college and service-learning. Community College Journal, 64(6), 15-19.

[4] Berry, J. W. (2001). A psychology of immigration. Journal of social issues, 57(3), 615-631.

[5] Bringle, R.G., \& Hatcher, J.A. (1995). A service-learning curriculum for faculty. Michigan Journal of Community Service Learning, 2, $112-122$.

[6] Byers, L. G., \& Gray, K. (2012). The meaning of service learning in an MSW Course. Journal of Teaching in Social Work, 32(3), 257-267. doi:10.1080/08841233.2012.688095

[7] Chupp, M. G., \& Joseph, M. L. (2010). Getting the most out of service learning: maximizing student, University and community impact. Journal of Community Practice, 18(2-3), 190-212. doi:10.1080/10705422.2010.487045.

[8] Darby, A., Longmire-Avital, B., Chenault, J., \& Haglund, M. (2013). Students' motivation in academic service-learning over the course of the semester. College Student Journal, 47(1), 185-191.

[9] Elwell, M. D. \& Bean S. M. (2001). Editors' choice: The efficacy of service-learning for community college ESL students. Community College Review, 28(4), 47-61. doi:10.1177/009155210102800403.

[10] Fitzgerald, C. M. (2009, May). Language and community: Using service learning to reconfigure the multicultural classroom. Language and Education, 23(3), 217-231. doi:10.1080/09500780802510159.

[11] Gass, S. M., \& Selinker, L. (2001). Second Language Acquisition: An introductory course (Second ed.). Mahwah, NJ: Lawrence Erlbaum Associates.

[12] Gerstenblatt, P., \& Gilbert, D. J. (2014). Framing service learning in social work: An interdisciplinary elective course embedded within a university-community partnership. Social Work Education, 33(8), 1037-1053. doi:10.1080/02615479.2014.935731.

[13] Glicker, E. R. I. C. (2006). Service-learning for academic literacy in adult ESL programs. The CATESOL Journal, $18(1), 40-47$.

[14] Hagan, M. (2004). Acculturation and an ESL program: A service learning project. Journal of Multicultural Counseling and Development, 32, 443-448.

[15] Heuser, L. (1999). Service-learning as a pedagogy to promote the content, cross-cultural, and language-learning of ESL students. TESL Canada Journal, 17(1), 54-71. doi:http://dx.doi.org/10.18806/tesl.v17i1.880.

[16] Hildenbrand, S. M., \& Schultz, S. M. (2015). Implementing Service Learning in pre-service teacher coursework. Journal of Experiential Education, 38(3), 262-279. doi:10.1177/1053825915571748.

[17] Jacoby, B. (1996). Service-learning in higher education: concepts and practices. San Francisco, CA: Jossey-Bass

[18] Kinsely, C. (1994). What is community service learning? Vital Speeches of the Day, 61(2), 40-43.

[19] Kolb, D. A. (1981). Learning styles and disciplinary differences. The modern American college, 1, 232-255.

[20] Kolb, D. A. (1984). Experiential learning. New Jersey, Eaglewood Cliffs.

[21] Leeman, J. (2011). Standards, commodification, and critical service learning in minority language communities. The Modern Language Journal, 95(2), 300-303. doi:10.1111/j.1540-4781.2011.01184.x.

[22] Lovat, T., \& Clement, N. (2016). Service learning as holistic values pedagogy. Journal of Experiential Education, 39(2), 115129. doi:10.1177/1053825916628548.

[23] Mahasneh, R., Tawalbeh, A., Al-Smadi, R., Ghaith, S., \& Dajani, R. (2012, November). Integrating service learning in Jordanian higher education. Innovations in Education and Teaching International, 49(4), 415-425. doi:10.1080/14703297.2012.728874. 
[24] Marlow, S. (2007, July). Creating Authentic Dialog: ESL Students as recipients of service learning. Retrieved December 01, 2016, from http://iteslj.org/Techniques/Marlow-ServiceLearning.html

[25] Mass-Weigert, K. (1998). Academic service-learning experiences: Its meaning and relevance. In R. Rhoads and J. Howard (Eds.), Academic service-learning: A pedagogy of action and reflection. San Francisco: Jossey-Bass Publishers.

[26] Mcclam, T., Diambra, J. F., Burton, B., Fuss, A., \& Fudge, D. L. (2008). An analysis of a service-learning project: students' expectations, concerns, and reflections. Journal of Experiential Education, 30(3), 236-249. doi:10.5193/jee.30.3.236

[27] Minor, J. M. (2001, April). Using service-learning as part of an ESL program. Retrieved December 01, 2016, from http://iteslj.org/Techniques/Minor-ServiceLearning.html.

[28] Molee, L. M., Henry, M. E., Sessa, V. I., \& Mckinney-Prupis, E. R. (2010). Assessing learning in service-learning courses through critical reflection. Journal of Experiential Education, 33(3), 239-257. doi:10.5193/jee33.3.239.

[29] Nation Service-Learning Clearinghouse (2005). Retrieved by Mcclam, T., Diambra, J. F., Burton, B., Fuss, A., \& Fudge, D. L. on December 5, 2005 from http://servicelearning.org/.

[30] National Youth Leadership Council. (2016, December 07). What is service-learning? Retrieved February 15, 2017, from https://nylc.org/service-learning/.

[31] Russell, N. M. (2007). Teaching more than English: Connecting ESL students to their community through service learning. Phi Delta Kappan, 88(10), 770-771. doi:10.1177/003172170708801015

[32] Ryan, L. B., \& Callahan, J. (2002). Making connections: Service-learning competencies and beginning teacher standards. The Teacher Educator, 38(2), 126-140. doi:10.1080/08878730209555312.

[33] Scott, D. L. (2008). Service learning: The road from the classroom to community-based macro intervention. Journal of Policy Practice, 7(2-3), 214-225. doi:10.1080/15588740801938068.

[34] Sperling, R. (2007). Service-learning as a method of teaching multiculturalism to white college students. Journal of Latinos and Education, 6(4), 309-322. doi:10.1080/15348430701473454.

Varrick Douglas Jr. is a United States citizen. He received his M.A. in applied linguistics from the University of Illinois at Chicago in 2006.

$\mathrm{He}$ is currently serving as Program Coordinator of Northern Virginia Community College's American Language and Culture Institute (ACLI) in Alexandria, VA. where his main responsibilities are developing, coordinating, and managing the Alexandria ACLI courses for international ESOL students. His primary experience is in higher education as a faculty member in the United States and overseas, including teaching in South Korea and the Sultanate of Oman. He has written ESOL educational materials that include "First Year English" (Alexandria VA, Stickcape Publishing 2014) and "The TOEFL Pocket Vocabulary Guide" (Alexandria VA, Stickcape Publishing 2014). He is currently researching the ways and means of reviewing ESOL textbooks for optimum efficacy in pedagogical practices. 